\title{
Desvendando a jornada escolar brasileira ${ }^{1}$
}

\author{
Understanding the Brazilian school day \\ Comprendre la journée de l'école Brésilienne
}

Cláudia da Mota Darós Parente ${ }^{2}$ Universidade Estadual Paulista

Resumo: O artigo tem como objetivo sistematizar os principais elementos constitutivos da jornada escolar brasileira, evidenciando diferentes tipos e formas de organização da educação básica. Neste ensaio teórico, faz-se um exercício de análise e decomposição da jornada escolar, destacando dois condicionantes: turnos escolares e infraestrutura. A análise da jornada escolar focalizou cinco elementos: currículo escolar, atividades complementares, recreio, alimentação escolar e tempo de cuidado. $\mathrm{O}$ artigo mostra que as relações entre esses elementos demarcam diferentes configurações da jornada escolar (parcial e integral) e ressalta a importância de uma reorientação de política pública no que se refere à ampliação da jornada escolar.

Palavras-chave: Jornada Escolar. Educação em Tempo Integral. Política Educacional.

Abstract: The article aims to systematize the main constituent elements of the Brazilian school day, evidencing different types and ways to organise the basic education. In this theoretical essay, an exercise of analysis and decomposition of the school day is made, highlighting two conditioning factors: school shifts and infrastructure. The analysis of the school day focused on five elements: school curriculum, extracurricular activities, break, school meal and care time. The article shows that the relationships between these elements delimit different configurations of the school day (half-day school and full-day day) and emphasizes the importance of a reorientation of public policy regarding the extension of the school day.

Key words: School Day. Full-time Education. Education Policy.

Résumé: L’article vise à systématiser les principaux éléments constitutifs de la journée scolaire brésilienne, en mettant en évidence différents types et formes d'organisation de l'éducation. Dans cet essai théorique, un exercice d'analyse et de décomposition de la journée scolaire est effectué, mettant en évidence deux facteurs conditionnants: les quarts de travail et les infrastructures. L'analyse de la journée scolaire a porté sur cinq éléments: programme scolaire obligatoire, activités complémentaires, pause, alimentation scolaire et temps de garde. L'article montre que les relations entre ces éléments démarquent différentes

1 O artigo foi elaborado durante a pesquisa de Pós-Doutorado realizada na Universidade de Salamanca (Espanha) e intitulada "Modelos e Experiências de Jornada Escolar na União Europeia: contribuições para a análise das políticas de educação integral em tempo integral no Brasil", com financiamento da Fundação de Amparo à Pesquisa do Estado de São Paulo (FAPESP).

2 Doutora. Professora do Departamento de Administração e Supervisão Escolar (DASE) - FFC/Campus Marília e dos Programas de Pós-Graduação em Educação (Marília e Presidente Prudente). Universidade Estadual Paulista - UNESP. E-mail: claudia.daros@unesp.br. ORCID: https://orcid.org/0000-0003-02508935. Lattes: http://lattes.cnpq.br/3896522242990616. 
configurations de la journée scolaire (partielle et complète) et souligne l'importance d'une réorientation de la politique publique en matière de prolongation de la journée scolaire.

Mots-clés: Journée scolaire. Éducation à temps plein. Politique éducative.

Recebido em: 29 de agosto de 2019 Aceito em: 25 de setembro de 2019

\section{Introdução}

A educação em tempo integral está na agenda político-educacional e, consequentemente, muitas políticas têm sido formuladas e implementadas com vistas a ampliar o atendimento em tempo integral, de forma a cumprir a meta 6 do Plano Nacional de Educação (BRASIL, 2014a).

No meio acadêmico, a educação em tempo integral também tem sido alvo de várias pesquisas. Pesquisadores de diversos estados e universidades brasileiras já se dedicaram à temática e desenvolveram uma série de estudos, inclusive analisando políticas e experiências específicas sob as mais diferentes perspectivas. No entanto, há muito ainda a ser pesquisado.

Investigar a educação em tempo integral significa adentrar num universo mais amplo, aqui denominado tempos escolares. A temática dos tempos escolares abrange as mais variadas categorias temporais que se vinculam à educação escolar: duração da escolarização compulsória, semana escolar, calendário escolar, períodos de férias, jornada escolar (ESCOLANO BENITO, 1992), início da escolarização, antecipação da escolarização, ampliação da escolarização, formas de organização da escolarização, seriação, multisseriação, ciclos, educação em tempo integral (PARENTE, 2015). Os tempos escolares são construções sócio-históricas e culturais. Isso justifica, em grande medida, as mudanças e alterações nos arranjos temporais da escola, em cada sociedade e em cada momento histórico. Justifica inclusive o fato de, no Brasil, privilegiar-se o estudo da "educação em tempo integral" em lugar de investigar a "jornada escolar".

No Brasil, quase não se discute jornada escolar. Em outras palavras: no contexto brasileiro estudar a jornada escolar é sinônimo de pesquisar sobre educação em tempo integral. As opções político-educacionais feitas, sobretudo no início do século XX, talvez possam explicar essas escolhas conceituais e acadêmicas. O que chama a atenção é o fato de que, embora o país conviva, predominantemente, com uma jornada parcial, pouco se faz menção a ela. 
Historicamente, o cenário em defesa de uma escola de tempo ampliado, com vistas a uma formação mais integral, parece ter direcionado a atenção de pesquisadores e policymakers a um "vir-a-ser" (jornada integral). Muitos esquecem que os adjetivos "parcial" e "integral" fazem referência a tipos de jornada escolar e, portanto, seria importante uma análise conjunta (e dialética) dos dois tipos de jornada escolar: parcial e integral.

Muitos pesquisadores e policymakers, ao privilegiarem a temática "educação em tempo integral", focalizam a discussão nas experiências que ampliam o tempo do aluno na escola. Ao fazerem isso, muitos deixam de lado a maior parte das escolas brasileiras, ou seja, aquelas com jornada parcial. Além disso, muitas vezes, jornada escolar integral é vista como uma unidade ou mesmo uma totalidade. Quase nunca os estudos se preocupam em desvendar suas partes, como se constitui, quais são os elementos que (con)formam a jornada escolar, seja ela parcial ou integral.

Ademais, em virtude das características de um país federativo como o Brasil, são muitas as possibilidades organizativas em relação à jornada escolar, o que sugere uma multiplicidade de tipos de oferta no âmbito da educação básica.

Assim, em que pese a relevância da temática "educação em tempo integral", neste artigo, busca-se rever o foco da discussão, ainda que a jornada integral também esteja sendo devidamente considerada.

Neste ensaio teórico pretende-se sistematizar os principais elementos constitutivos da jornada escolar brasileira, evidenciando diferentes tipos e formas de organização da educação básica.

Primeiramente, será apresentado um breve histórico da constituição da jornada escolar brasileira, sem a pretensão de que seja completo. Nesse histórico, deseja-se chamar a atenção para as mudanças que ocorreram no começo do século XX, em especial, para a substituição da jornada integral (de dia inteiro) pela jornada parcial (de meio período) e a criação dos turnos escolares.

Em seguida, pretende-se fazer um exercício de análise e decomposição da jornada escolar. Em primeiro lugar, serão apresentados dois elementos condicionantes da escola pública brasileira (e da jornada escolar): os turnos escolares e as condições de infraestrutura. Em segundo lugar, far-se-á um exercício de decomposição da jornada escolar, em destaque para os seguintes elementos: currículo escolar, atividades complementares, recreio, alimentação escolar e tempo de cuidado. As relações entre esses elementos resultam em diferentes tipos e formas de organização da educação básica. Justamente por isso, em último 
lugar, serão apresentados diferentes formatos de compor a jornada escolar do aluno, na escola ou sob a sua responsabilidade.

Espera-se que a desconstrução da jornada escolar possa auxiliar na organização de formatos mais adequados aos sujeitos da educação e demarque alternativas e possibilidades frente a contextos de restrições do papel do Estado e do financiamento público.

\section{Constituição da Jornada Escolar Brasileira}

No final do século XIX e início do século XX, a então escola primária funcionava com jornada integral, ou seja, manhã e tarde, das $10 \mathrm{~h}$ às $15 \mathrm{~h}, 5$ horas por dia em 6 dias da semana. Em 1904, a carga horária passou a ser cumprida das 11 h às 16 horas, com trinta minutos de recreio. Os estudos de Souza (1999), relativos ao estado de São Paulo, mostraram que, em 1908, pela primeira vez, foram criados desdobramentos de horário, ou seja, os tão conhecidos turnos escolares. Com isso, algumas escolas passaram a funcionar em dois períodos: das 8 às 12 horas (classes masculinas) e das $12 \mathrm{~h} 30$ às $16 \mathrm{~h} 30$ (classes femininas), ambas com meia hora de recreio.

Faria Filho e Vidal (2000) também mencionam a implementação dos turnos escolares em algumas escolas de São Paulo e de Minas Gerais. Os autores fazem alusão aos planos de edificações escolares da década de 1930: citam propostas de Almeida Júnior para a edificação de prédios escolares em São Paulo para serem ocupados em dois turnos; e fazem referência à proposta de Anísio Teixeira, no Rio de Janeiro (antigo Distrito Federal), de construir diferentes tipos de prédios escolares a depender da localização e da densidade populacional: escolas tipo “mínimo”, escolas nucleares e escolas-parque associadas a cada quatro escolas-nucleares.

A pesquisa de Oliveira (2007) apresenta dados sobre o estudo que, na década de 1930, foi feito pela Diretoria de Ensino do estado de São Paulo, relacionando os dados da população em idade escolar (7 a 14 anos) e a quantidade de vagas disponíveis, com a finalidade de identificar a quantidade de escolas a serem construídas, já prevendo a utilização do prédio escolar em dois turnos (desdobramento de horário). A autora também menciona que, já na década de 1930, Anísio Teixeira tinha como proposição a existência de turnos duplos (manhã ou tarde) nas escolas-classe, com a diferença que, no contraturno (manhã ou tarde), as crianças iriam para a escola-parque ou parque escolar.

Assim, nas primeiras décadas do século XX, havia escolas funcionando em dois turnos, com 4 horas diárias, e escolas funcionando em jornada integral (manhã e tarde), com 
5 horas diárias (SOUZA, 1999; OLIVEIRA, 2007). Em 1929, sob o argumento da democratização e ampliação de vagas, foi criado o "tresdobramento", ou seja, escolas com três turnos. Nesse formato de três turnos, a jornada escolar diária reduziu-se a 3 horas naquele contexto. Oliveira (2007) relata que, em geral, o "tresdobramento" funcionava das 7 h50 às $10 h 50$, das 11 ho5 às 14 h e das 14 h 15 às $17 \mathrm{~h} 15$.

É importante destacar que os turnos escolares atuavam (e ainda atuam) como medida econômica para a duplicação de vagas. Ao longo da história da educação brasileira essa medida, em alguns contextos, possibilitou a triplicação ou mesmo a quadriplicação de vagas nas escolas públicas, a exemplo do modelo de quatro turnos: $7 \mathrm{~h}$ às $11 \mathrm{~h} ; 11 \mathrm{~h}$ às $15 \mathrm{~h} ; 15 \mathrm{~h}$ às $19 \mathrm{~h} ; 19 \mathrm{~h}$ às $23 \mathrm{~h}$.

Os estudos citados mostram que foi justamente nesse período histórico, em virtude das opções pelos turnos escolares e, consequentemente, pela redução da jornada escolar que, no Brasil, surgiu a dualidade entre jornada parcial e jornada integral. O fato é que esse modelo de escola com turnos e consequente jornada reduzida tornou-se predominante no país a partir de então.

Ao longo do século XX, algumas experiências foram significativas para propor mudanças nesse cenário de turnos escolares e de jornada escolar reduzida, embora tenham sido experiências focalizadas em contextos específicos e pouco abrangentes. Ainda que existam várias ações de ampliação da jornada escolar espalhadas por todo o Brasil, no âmbito acadêmico, comumente, faz-se menção recorrente às seguintes experiências:

1) Centro Educacional Carneiro Ribeiro (CECR), implementado em Salvador, na década de 1950, no então ensino primário, com jornada escolar de 8 horas, sendo 4 horas de permanência na Escola-Classe e 4 horas de permanência na Escola-Parque, assim como previa seu idealizador, Anísio Teixeira. Os alunos que frequentavam a Escola-Classe pela manhã iam à Escola-Parque no período da tarde e vice-versa, o que permitia a duplicação do atendimento (ÉBOLI, 1969).

2) Classes Experimentais implementadas na década de 1950 no então ensino secundário, experiência nascida no Instituto de Educação "Professor Alberto Conte", localizado na cidade de São Paulo. A experiência teve a adesão de escolas públicas e privadas em oito estados brasileiros. Embora a jornada escolar não fosse o foco, algumas escolas implementaram a jornada integral (manhã e tarde) (DALLABRIDA, 2017).

3) Escolas-Parque de Brasília, implementadas a partir da década de 1960, com proposta similar àquela do Centro Educacional Carneiro Ribeiro, de Salvador (XAVIER, 2017).

4) Ginásios Vocacionais, herdeiros das Classes Experimentais, implementados na década de 1960 em seis escolas nos municípios paulistas de Barretos, Batatais, Rio Claro, 
Americana, São Paulo e São Caetano do Sul, nas quais os alunos tinham uma jornada escolar de 9 horas, sendo uma hora de almoço (NEVES, 2010; CHIOZZINI; MARQUES, 2016).

5) Centros Integrados de Educação Pública (CIEP), implementados a partir da década de 1980, no estado do Rio de Janeiro e, pontualmente, em outras cidades/estados brasileiros. A jornada do aluno era de nove horas, incluindo a refeição (MIGNOT, 1989; CAVALIERE; COELHO, 2003).

6) Jornada Única do Ciclo Básico na rede estadual de ensino de São Paulo, implementada na década de 1980 nas duas primeiras séries do então ensino de primeiro grau. O programa ampliou a jornada do aluno de 4 para 6 horas diárias e também a jornada do professor para 40 horas (SILVA et al., 1993).

7) Centros de Atenção Integral à Criança (CAIC), implementados na década de 1990. O projeto arquitetônico indicava a possibilidade de jornada integral, embora nem sempre isso tenha ocorrido (AMARAL SOBRINHO; PARENTE, 1995).

As experiências citadas não encerram várias outras tentativas de ampliação da jornada escolar, porém ilustram o caráter focalizado e fragmentado das políticas educacionais.

No início dos anos 2000, várias outras experiências proliferaram pelo país, alterando a jornada escolar. Em 2007, é importante mencionar a criação do Programa Mais Educação no âmbito do governo federal, programa que, até o momento, foi a experiência de maior impacto em termos de atendimento em jornada integral (PARENTE, 2014), embora, como política de governo, tenha sido marcado pela descontinuidade política, administrativa e financeira.

\section{Jornada Escolar Brasileira: contexto atual}

Apesar de a trajetória histórica anterior mostrar experiências de ampliação da jornada escolar, em 2007 definiu-se legalmente, em termos de horas, a diferença entre jornada parcial e jornada integral. É importante mencionar que essa definição é muito específica da realidade brasileira.

Desde a aprovação da Lei de Diretrizes e Bases, em 1996, determinou-se a progressiva ampliação do “[...] período de permanência na escola [...]” no âmbito do ensino fundamental, ou seja, que esta etapa seja “[...] progressivamente em tempo integral, a critério dos sistemas de ensino". Nas disposições transitórias, menciona-se que "serão conjugados todos os esforços objetivando a progressão das redes escolares públicas urbanas de ensino fundamental para o 
regime de escolas de tempo integral" (BRASIL, 1996, arts. 34 e 87). Em 2001, na lei que aprovou o Plano Nacional de Educação, entre os objetivos e metas para o ensino fundamental indicava-se: "ampliar, progressivamente a jornada escolar visando expandir a escola de tempo integral, que abranja um período de pelo menos sete horas diárias [...]” (BRASIL, 2001).

Em 2007, o decreto que regulamentou o Fundo de Manutenção e Desenvolvimento da Educação Básica e de Valorização dos Profissionais da Educação (Fundeb), para fins de distribuição de recursos financeiros, definiu a jornada integral como “ $[$...] jornada escolar com duração igual ou superior a sete horas diárias, durante todo o período letivo, compreendendo o tempo total que um mesmo aluno permanece na escola ou em atividades escolares" (BRASIL, 2007, art. 20).

Em 2013, em virtude de algumas alterações na LDB, reforçou-se a diferença entre jornada parcial e integral no contexto da educação infantil: "[ [... 4 (quatro) horas diárias para o turno parcial e de 7 (sete) horas para a jornada integral” (BRASIL, 1996; 2013).

Num país continental e federativo como o Brasil, União, Estados e Municípios têm autonomia para criar seus próprios sistemas de ensino e ofertar educação básica por meio de sua própria rede escolar. Nesse cenário de descentralização, haverá uma multiplicidade de formas de organizar a jornada escolar, contanto que os entes federativos respeitem a definição legal que, atualmente, estabelece o mínimo de 4 horas para a jornada parcial e o mínimo de 7 horas para a jornada integral.

Diante dessa definição legal, para conhecer a configuração da jornada escolar no atual contexto brasileiro pode-se, primeiramente, recorrer às informações relativas ao número médio de horas-aula diária ${ }^{3}$.

Conforme a Tabela 1, os dados do Censo Escolar mostram que os alunos brasileiros que frequentam a educação infantil pública têm, em média, 5,9 horas-aula diária; no ensino fundamental público possuem, em média, 4,6 horas-aula diária; no ensino médio público têm, em média, 5,o horas-aula diária.

A Tabela 1 mostra também as diferenças em termos de etapas e de unidades da federação. No âmbito da educação infantil, chamam a atenção os estados da região Sul (Paraná, Rio Grande do Sul e Santa Catarina) que oferecem, em média, 7,0, 7,1 e 7,6 horas-

\footnotetext{
${ }^{3}$ Conforme consulta feita eletronicamente ao Instituto Nacional de Estudos e Pesquisas Educacionais Anísio Teixeira (INEP), na construção desse indicador (número médio de horas-aula diária), não estão incluídas as atividades complementares, apenas as turmas de escolarização. O indicador, portanto, não contabiliza todos os formatos de educação em tempo integral.
} 
aula, respectivamente. Não obstante, o estado do Amapá oferece, em média, apenas 4,1 horasaula diária nesta etapa da educação básica, muito abaixo da média nacional.

No âmbito do ensino fundamental, os estados de Santa Catarina e de Mato Grosso possuem a menor média (4,1), enquanto São Paulo e Distrito Federal oferecem, em média, 5,1 horas-aula por dia.

No que se refere ao ensino médio, Pernambuco é o estado que apresenta a maior média, com 6,8 horas-aula por dia, muito acima da média nacional. Os estados do Pará, da Bahia e de Santa Catarina são os que oferecem a menor média de horas-aula diária $(4,4)$.

Tabela 1: Número Médio de Horas-Aula Diária por Etapa da Educação Básica Pública Brasil e Unidades da Federação - 2018

\begin{tabular}{|c|c|c|c|}
\hline $\begin{array}{l}\text { UNIDADE DA } \\
\text { FEDERAÇÃO }\end{array}$ & $\begin{array}{l}\text { EDUCAÇÃO } \\
\text { INFANTIL }\end{array}$ & $\begin{array}{c}\text { ENSINO } \\
\text { FUNDAMENTAL }\end{array}$ & $\begin{array}{l}\text { ENSINO } \\
\text { MÉDIO }\end{array}$ \\
\hline Brasil & 5,9 & 4,6 & 5,0 \\
\hline Acre & 4,7 & 4,2 & 5,4 \\
\hline Alagoas & 5,3 & 4,5 & 5,4 \\
\hline Amapá & 4,1 & 4,3 & 5,0 \\
\hline Amazonas & 4,2 & 4,3 & 4,6 \\
\hline Bahia & 5,4 & 4,5 & 4,4 \\
\hline Ceará & 4,8 & 4,3 & 5,6 \\
\hline Distrito Federal & 5,1 & 5,1 & 5,1 \\
\hline Espírito Santo & 5,0 & 4,7 & 5,6 \\
\hline Goiás & 6,5 & 4,8 & 5,3 \\
\hline Maranhão & 4,2 & 4,2 & 4,9 \\
\hline Mato Grosso & 5,3 & 4,1 & 4,6 \\
\hline Mato Grosso do Sul & 6,3 & 4,4 & 4,8 \\
\hline Minas Gerais & 5,8 & 4,4 & 4,5 \\
\hline Pará & 4,4 & 4,3 & 4,4 \\
\hline Paraíba & 6,1 & 4,6 & 5,7 \\
\hline Paraná & 7,0 & 4,4 & 4,5 \\
\hline Pernambuco & 5,0 & 4,5 & 6,8 \\
\hline Piauí & 4,4 & 4,9 & 5,3 \\
\hline Rio de Janeiro & 6,0 & 4,9 & 5,7 \\
\hline Rio Grande do Sul & 7,1 & 4,3 & 4,8 \\
\hline Rio Grande Norte & 4,3 & 4,5 & 4,9 \\
\hline Rondônia & 4,5 & 4,2 & 4,7 \\
\hline Roraima & 4,8 & 4,3 & 5,2 \\
\hline Santa Catarina & 7,6 & 4,1 & 4,4 \\
\hline São Paulo & 6,7 & 5,1 & 5,2 \\
\hline Sergipe & 4,9 & 4,4 & 5,1 \\
\hline Tocantins & 5,3 & 4,8 & 5,0 \\
\hline
\end{tabular}

Fonte: Brasil (2018a). Elaborada pela autora.

Os dados relativos ao número médio de horas-aula diária evidenciam a prevalência da jornada parcial sobre a jornada integral. O Relatório de Monitoramento das Metas do Plano Nacional de Educação revela que, no âmbito de toda a educação básica pública, 82,6\% dos 
alunos estudam em jornada parcial e apenas $17,4 \%$ estudam em jornada integral, conforme mostra a Tabela 2. Em termos de escolas, 71,4\% funcionavam em jornada parcial. Apenas 28,6\% das escolas públicas brasileiras ofereciam matrículas com jornada integral.

Tabela 2: Jornada Escolar na Educação Básica Pública - Brasil - 2018

\begin{tabular}{c|c|c}
\hline TIPO DE JORNADA & ALUNOS (\%) & ESCOLAS (\%) \\
\hline Jornada Parcial & 82,6 & 28,4 \\
\hline Jornada Integral & 17,4 & 28,6 \\
\hline
\end{tabular}

Fonte: Brasil (2018b). Elaborada pela autora

No entanto, os dados nacionais gerais não mostram as diferenças em termos de unidades da federação. A Tabela 3, por sua vez, permite evidenciar que, diante da meta nacional de ampliar as matrículas de educação em tempo integral a pelos menos $25 \%$ dos alunos da educação básica, atualmente, existem dois grupos: estados que já ultrapassaram a meta (Tocantins, Ceará, Pernambuco e Paraíba) e estados que ainda não atingiram a meta ${ }^{4}$. Nesse último grupo, destacam-se os estados do Amapá e de Roraima que ainda possuem apenas 4,0 e 4,7\% de seus alunos em tempo integral, respectivamente.

Tabela 3: Jornada Integral na Educação Básica Pública - Brasil, por Unidade da Federação - 2018.

\begin{tabular}{l|c}
\hline \multicolumn{1}{c|}{ UNIDADE DA FEDERAÇÃO } & \% \\
\hline Brasil & $\mathbf{1 7 , 4}$ \\
\hline Acre & 11,4 \\
\hline Alagoas & 18,1 \\
\hline Amapá & 4,0 \\
\hline Amazonas & 13,6 \\
\hline Bahia & 22,3 \\
\hline Ceará & 30,0 \\
\hline Distrito Federal & 7,2 \\
\hline Espírito Santo & 8,6 \\
\hline Goiás & 17,7 \\
\hline Maranhão & 17,8 \\
\hline Mato Grosso & 13,0 \\
\hline Mato Grosso do Sul & 13,5 \\
\hline Minas Gerais & 14,3 \\
\hline Pará & 10,4 \\
\hline Paraíba & 26,2 \\
\hline Paraná & 16,4 \\
\hline Pernambuco & 27,3 \\
\hline Piauí & 22,8 \\
\hline
\end{tabular}

\footnotetext{
${ }^{4}$ Os dados não mostram diferenças entre as redes de ensino (federal, estaduais, distrital e municipais).
} 


\begin{tabular}{l|c}
\hline Rio de Janeiro & 20,3 \\
\hline Rio Grande do Sul & 16,7 \\
\hline Rio Grande Norte & 16,1 \\
\hline Rondônia & 7,8 \\
\hline Roraima & 4,7 \\
\hline Santa Catarina & 18,2 \\
\hline São Paulo & 15,5 \\
\hline Sergipe & 13,2 \\
\hline Tocantins & 32,1 \\
\hline \multicolumn{1}{c}{ Fonte: Brasil (2018a). Elaborada pela autora. }
\end{tabular}

Com base nesse cenário, é importante ilustrar como as unidades federativas organizam suas jornadas (parcial e/ou integral). Diante das muitas possibilidades organizativas, o Quadro 1 mostra um esquema básico de jornada parcial com uma carga horária de 4 h30 na parte da manhã e na parte da tarde, assim como um esquema básico de jornada integral com carga horária de 7 h30.

Quadro 1: Jornada Escolar no Brasil

\begin{tabular}{|c|c|c|c|c|c|c|c|}
\hline \multicolumn{2}{|c|}{$\begin{array}{l}\text { JORNADA PARCIAL } \\
\text { MANHÃ }\end{array}$} & \multicolumn{2}{|c|}{$\begin{array}{c}\text { JORNADA PARCIAL } \\
\text { TARDE }\end{array}$} & \multicolumn{4}{|c|}{$\begin{array}{l}\text { JORNADA INTEGRAL } \\
\text { MANHÃ E TARDE }\end{array}$} \\
\hline 7h30 -8h20 & $1^{a}$ Sessão & $13 \mathrm{~h}-13 \mathrm{~h} 50$ & $1^{\mathrm{a}}$ Sessão & 7h30 -8h20 & $1^{\mathrm{a}}$ Sessão & $12 \mathrm{~h}-13 \mathrm{~h}$ & ALMOÇO \\
\hline $8 \mathrm{~h} 20-9 \mathrm{~h} 10$ & $2^{\text {a }}$ Sessão & $13 \mathrm{~h} 50-14 \mathrm{~h} 4 \mathrm{O}$ & $2^{\mathrm{a}}$ Sessão & $8 \mathrm{~h} 20-9 \mathrm{~h} 10$ & $2^{\mathrm{a}}$ Sessão & $13 \mathrm{~h}-13 \mathrm{~h} 50$ & $6^{\mathrm{a}}$ Sessão \\
\hline $9 \mathrm{~h} 10-1 \mathrm{oh}$ & $3^{\text {a }}$ Sessão & $14 \mathrm{~h} 40-15 \mathrm{~h} 30$ & $3^{\mathrm{a}}$ Sessão & $9 \mathrm{~h} 10-10 \mathrm{~h}$ & $3^{\text {a }}$ Sessão & $13 \mathrm{~h} 50-14 \mathrm{~h} 10$ & RECREIO \\
\hline 10h-10h20 & RECREIO & $15 \mathrm{~h} 30-15 \mathrm{~h} 50$ & RECREIO & 10h-10h20 & RECREIO & $14 \mathrm{~h} 10-15 \mathrm{~h}$ & $7^{\mathrm{a}}$ Sessão \\
\hline $10 \mathrm{~h} 2 \mathrm{O}-11 \mathrm{~h} 10$ & $4^{\mathrm{a}}$ Sessão & $15 \mathrm{~h} 50-16 \mathrm{~h} 40$ & $4^{\mathrm{a}}$ Sessão & $1 \mathrm{oh} 2 \mathrm{O}-1 \mathrm{~h} 1 \mathrm{O}$ & $4^{\mathrm{a}}$ Sessão & & \\
\hline $11 \mathrm{~h} 1 \mathrm{O}-12 \mathrm{~h}$ & $5^{\text {a }}$ Sessão & $16 \mathrm{~h} 40-17 \mathrm{~h} 30$ & $5^{\mathrm{a}}$ Sessão & $11 \mathrm{~h} 10-12 \mathrm{~h}$ & $5^{\text {a }}$ Sessão & & \\
\hline \multicolumn{2}{|c|}{$4 \mathrm{~h} 30$} & \multicolumn{2}{|c|}{ 4h30 } & \multicolumn{4}{|c|}{$7 \mathrm{~h} 30$} \\
\hline
\end{tabular}

Elaborado pela autora.

$\mathrm{Na}$ organização da jornada escolar, devem ser levados em conta alguns elementos, entre eles: horário de entrada, horário de saída, tempo de cada aula (sessão), quantidade de sessões, tempo de intervalo/recreio/almoço. As unidades federativas e as redes de ensino têm autonomia para definir esses elementos e, em muitos casos, há também relativa autonomia das escolas, o que resulta em múltiplas possibilidades de organização da jornada escolar no contex to brasileiro para além do esquema básico apresentado. 


\section{Jornada Escolar e Turno Escolar}

Conforme exposto anteriormente, o Brasil iniciou o século XX com uma jornada integral (de dia inteiro) e já nas primeiras décadas fez a opção pelos turnos escolares como forma de ampliação de vagas para fins de democratização do acesso à educação escolar.

O acesso à educação pública para todos precisa ser garantido. No Brasil, desde 2009, a escolarização obrigatória vai $\operatorname{dos} 4$ aos 17 anos (BRASIL, 2009). Ainda que não faltem problemas no campo educacional, em termos de acesso, os dados estatísticos mostram que o Brasil vem avançando, principalmente, na faixa etária da escolarização obrigatória. A taxa de escolarização na faixa etária entre o e 3 anos é de 32,7\%; entre 4 e 5 anos é de $91,7 \%$; entre 6 a 14 anos é de 99,2\%; na faixa etária de 15 a 17 é de 87,2\% (IBGE, 2018). Infelizmente, esses dados não mostram um problema sério que ainda persiste no Brasil: as disparidades regionais.

Ao longo do século XX, a ampliação do acesso à educação escolar ocorreu de diferentes maneiras, inclusive por meio da existência dos turnos escolares, ou seja, os turnos escolares cumpriram uma função importante, já que permitiram a duplicação, triplicação e até quadriplicação de vagas nas escolas públicas, ainda que isso tenha produzido consequências para a qualidade da educação.

Do ponto de vista econômico, a utilização da escola em turnos é uma opção que reduz custos. No entanto, do ponto de vista educacional, a permanência dos turnos escolares geralmente inviabiliza ações que possam melhorar a oferta da escolarização obrigatória. Consequentemente, dificulta a ampliação da jornada escolar e a utilização do prédio escolar para a oferta de atividades complementares/extracurriculares.

Atualmente, no cenário educacional brasileiro é possível encontrar, de forma geral, escolas com: apenas 1 turno (oferta escolar para apenas um grupo de alunos, manhã ou tarde); 2 turnos (geralmente, manhã e tarde, com oferta escolar para dois diferentes grupos de alunos); 3 turnos (manhã, tarde e noite, com oferta para três diferentes grupos de alunos). Conforme a Tabela 4, os dados do Censo Escolar indicam que a maior parte das escolas brasileiras $(50,2 \%)$ funciona com 2 turnos escolares; 29,7\% funciona com apenas 1 turno e 20,1\% funciona com 3 turnos. As escolas com apenas 1 turno escolar geralmente são escolas com até 50 matrículas e muitas delas referem-se a escolas localizadas na zona rural. Em termos de matrículas, 45,9\% dos alunos estudam em escolas com 2 turnos; 45,9\% em escolas com 3 turnos; e 8,2 em escolas de apenas 1 turno escolar. 
Tabela 4: Escolas e Matrículas na Educação Básica em função dos Turnos Escolares - Brasil.

\begin{tabular}{l|c|c}
\hline \multicolumn{1}{c|}{ TIPO } & $\begin{array}{c}\text { ESCOLAS } \\
\mathbf{\%}\end{array}$ & $\begin{array}{c}\text { MATRÍCULAS } \\
\mathbf{\%}\end{array}$ \\
\hline Escola com um turno & 29,7 & 8,2 \\
\hline Escola com dois turnos & 50,2 & 45,9 \\
\hline Escola com três turnos & 20,1 & 45,9 \\
\hline
\end{tabular}

Fonte: Brasil (2014b). Elaborado pela autora.

O fato é que, diante da universalização do ensino fundamental e da progressiva universalização de parte da educação infantil e do ensino médio, é preciso refletir sobre a estratégia dos turnos escolares, ainda pouco estudada no contexto brasileiro, reforçando as consequências de sua manutenção e desenvolvendo estudos sobre o impacto financeiro de sua progressiva eliminação.

Sabe-se, entretanto, que o cenário de racionalização e de minimização do papel do Estado e a crise do financiamento público estabelecem limites à eliminação dos turnos, tão naturalizados na educação brasileira. Do ponto de vista ideal, a eliminação dos turnos seria um bom caminho (não o suficiente) para a garantia de recursos físicos mais adequados à oferta da escolarização obrigatória.

Não é por acaso que a própria legislação educacional, em lugar da reversibilidade do turno único, optou pela progressividade e seletividade da educação em tempo integral, ou seja, a eliminação dos turnos escolares está estreitamente associada à implementação da jornada integral, devendo ocorrer de forma progressiva e restrita a uma parcela dos alunos da educação básica. Fortemente embasados nesses elementos, os sistemas de ensino vão criando suas próprias estratégias, dentro de seus limites financeiros, físicos, materiais e humanos. Analisar as estratégias que estão sendo criadas é imprescindível para compreender as especificidades e diferenças entre a oferta de escolarização por meio da jornada parcial e por meio da jornada integral. Para isso, é importante aprofundar a discussão das duas jornadas e relacioná-las aos princípios de igualdade e equidade.

\section{Jornada Escolar e Infraestrutura}

Tem-se como premissa básica que a defesa de uma escola pública de qualidade passa pela defesa do acesso a todos à escolarização obrigatória. No entanto, a oferta da 
escolarização obrigatória em condições desiguais leva, supostamente, a resultados diferentes. Infelizmente, os dados indicam que as escolas públicas, embora tenham melhorado ao longo das últimas décadas, ainda apresentam condicionantes materiais importantes.

Dados do Censo Escolar mostram algumas das disparidades existentes nas escolas públicas de todo o país. Apenas 48,9\% das escolas públicas de ensino fundamental possuem biblioteca ou sala de leitura, contra $81,6 \%$ das escolas privadas. Considerando-se apenas as redes municipais de ensino brasileiras, apenas 40,1\% possuem biblioteca ou sala de leitura. No quesito, quadra poliesportiva (coberta ou descoberta), 37,8\% das escolas públicas de ensino fundamental do país possuem quadra, contra 59,7\% das escolas privadas. Apenas $30 \%$ das redes municipais de ensino possuem quadra (BRASIL, 2018a).

Os dados evidenciam que as escolas públicas ainda carecem de infraestrutura mínima básica. As condições de infraestrutura, embora não sejam os únicos determinantes, condicionam a qualidade da educação básica. As condições materiais das escolas também condicionam a jornada escolar, seja ela parcial ou integral. Inclusive, as condições materiais da escola condicionam a decisão de se implementar a jornada integral na escola ou não.

Atualmente, no Brasil, muitos pesquisadores e policymakers defendem a jornada integral de forma compulsória e para todos, embora não haja consenso sobre a questão e nem sempre esteja respaldada em argumentos concretos. No entanto, já se destacou que há uma barreira material importante que impede a eliminação dos turnos e, consequentemente, a oferta de educação em tempo integral a todos. Por outro lado, as atuais condições de infraestrutura inibem, inclusive, a efetivação da jornada escolar, mínima, de 4 horas diárias. Frente a esse cenário, no processo de decisão política, não seria o caso de redefinir prioridades e reorientar a política pública?

Muitos policymakers têm utilizado como estratégia implementar a jornada integral em escolas que possuem melhor infraestrutura física, material e em termos de recursos humanos. Ou seja, estão optando por enriquecer o currículo escolar dos alunos que frequentam escolas com melhor infraestrutura, o que sugere o agravamento das disparidades entre as escolas públicas. Nessa lógica, as escolas que não possuem infraestrutura continuam sem as devidas condições de oferecer um currículo escolar mínimo e menos ainda de oferecer enriquecimento curricular.

Assim, diante dos limites financeiros para materializar a estratégia 6.3. do Plano Nacional de Educação (BRASIL, 2014a), relativa à ampliação e reestruturação das escolas públicas, é preciso definir prioridades por meio de critérios mais objetivos para que a garantia de uma escolarização obrigatória de qualidade não esteja submetida ao tipo de 
jornada (parcial ou integral). Para isso, é preciso analisar o que há em comum entre a jornada parcial e a jornada integral em suas várias configurações e delimitar o que deve ser para todos e o que é complementar para alguns provisoriamente.

\section{Jornada Escolar, Currículo Escolar e Atividades Complementares}

Quando os dados do Censo Escolar informam que, no ensino fundamental público brasileiro, os alunos possuem, em média, 4,6 horas-aula diária, o que, de fato, isso significa em termos de atividades escolares? Quando o Relatório de Monitoramento do Plano Nacional de Educação informa que 17,4\% dos alunos da educação básica pública estão em tempo integral, o que isso significa? Ou seja, diante da concomitância das jornadas parcial e integral na educação brasileira, o que as diferencia em termos de estrutura curricular? O que é o básico para todos e o que é complementar? Partindo-se do pressuposto de que as definições curriculares têm sempre como parâmetro a carga horária mínima prevista em termos anuais e a jornada escolar mínima de 4 horas, infere-se que qualquer ampliação da jornada escolar para além das 4 horas diárias teria relação com algo a mais para além do básico.

A legislação nacional e a legislação complementar dos entes federativos apresentam diretrizes curriculares para a organização da educação básica, ou seja, o que as escolas devem oferecer aos alunos em termos de currículo escolar.

A Lei de Diretrizes e Bases (LDB) define que a União, em colaboração com os Estados, o Distrito Federal e os Municípios, deve estabelecer “ $[$...] competências e diretrizes [...] que nortearão os currículos e seus conteúdos mínimos, de modo a assegurar formação básica comum". Define ainda a carga horária mínima anual e o número de dias letivos de efetivo trabalho escolar (800 horas e 200 dias, respectivamente), prevendo, recentemente, a progressividade da carga horária no âmbito do ensino médio (1400 horas). A LDB também determina que os currículos das diferentes etapas da educação básica “[...] devem ter base nacional comum, a ser complementada [...] por uma parte diversificada [...]”. Por fim, estabelece os conteúdos e componentes curriculares obrigatórios (BRASIL, 1996; BRASIL, 2013; BRASIL, 2017, grifo nosso).

As Diretrizes Curriculares Nacionais (DCN) para a Educação Básica, aprovadas em 2010, no que se refere às formas de organização curricular fazem menção aos componentes 
curriculares centrais obrigatórios e outros de modo flexível e variável, ou seja, a parte diversificada que “[...] enriquece e complementa a base nacional comum" (BRASIL, 2010, grifo nosso).

Por sua vez, a Base Nacional Comum Curricular (BNCC) deve assegurar os denominados direitos de aprendizagem. Entre os elementos fundantes da BNCC, está a definição de competências e diretrizes comuns, garantida a diversidade curricular; e a definição das aprendizagens essenciais, não apenas de conteúdos mínimos. Além disso, a Base destaca seu compromisso com a educação integral definida como “[ [...] construção intencional de processos educativos que promovam aprendizagens sintonizadas com as necessidades, as possibilidades e os interesses dos estudantes [...]”. Conforme a BNCC, o compromisso com a educação integral deve ocorrer “[...] independentemente da duração da jornada escolar" (BRASIL, 2018c, p. 11-14, grifo nosso).

A explicitação desses aspectos legais reforça uma vez mais o pressuposto de que a base nacional comum complementada por uma parte diversificada (o que condensaria o que a BNCC chama de direitos de aprendizagem e neste artigo será genericamente chamado de currículo escolar mínimo) está pautada na carga horária anual e diária mínima prevista em lei. Consequentemente, toda ampliação do tempo do aluno na escola para além desse mínimo deve ser interpretada como complementar.

O fato é que alguns entes federativos vêm ampliando a jornada escolar, o que leva a decisões em torno do currículo escolar. A questão é: como está ocorrendo essa ampliação? Quais elementos estão sendo ampliados ou quais elementos estão sendo introduzidos?

A depender da política de ampliação da jornada escolar efetivada em cada rede de ensino, haverá aumento da carga horária destinada aos conteúdos e componentes curriculares obrigatórios e/ou à parte diversificada.

Muitas redes de ensino vêm oferecendo o que a legislação denomina genericamente atividades complementares. Em 2007, após a regulamentação do Fundeb, o Censo Escolar passou a captar "aluno em tempo integral" por meio de turmas de escolarização de, no mínimo 7 horas ou “[ [...] quando a soma do período da escolarização e da atividade complementar realizada no contraturno configura, no mínimo, 7 horas diárias”. Conforme o Censo Escolar, as atividades complementares são "atividades de livre escolha que complementam a escolarização e o currículo obrigatório" (BRASIL, 2018d, grifo nosso).

As atividades complementares também são conhecidas como extracurriculares ou extraescolares. No entanto, algumas redes de ensino, ao formularem sua política de ampliação da jornada escolar e implementarem o tempo integral, tornam algumas atividades complementares compulsórias, ou seja, integram-se ao currículo escolar e o que seria 
extracurricular passa a ser curricular. Essa situação expressa a dificuldade de generalizar alguns conceitos diante da diversidade de políticas e práticas político-pedagógicas em vigor no país.

De forma geral, as atividades complementares referem-se à oferta de atividades esportivas (futebol, basquete, vôlei, judô etc.), atividades artísticas (dança, música, artesanato, teatro etc.), atividades recreativas, atividades de acompanhamento escolar, atividades relacionadas às línguas e às novas tecnologias. Porém, há muitas outras possibilidades. São atividades que enriquecem o currículo escolar e que oferecem novas oportunidades para o desenvolvimento integral das crianças, adolescentes e jovens em idade de escolarização obrigatória.

Em relação à organização curricular, considera-se essencial, em primeiro lugar, a garantia de uma escolarização obrigatória mínima, dos 4 aos 17 anos, por meio de um currículo escolar mínimo durante o tempo mínimo diário estabelecido na legislação: 4 horas. A partir disso, no processo de decisão política, diante dos elementos de progressividade e seletividade mencionados anteriormente, é preciso definir critérios objetivos para a oferta de enriquecimento curricular, o que levaria à ampliação da jornada escolar a determinadas turmas, escolas, faixas etárias, regiões ou sujeitos específicos. Nesse processo de decisão política, é preciso também refletir sobre os perigos de se criar novas desigualdades dentro da própria escola pública.

\section{Jornada Escolar, Recreio e Alimentação Escolar}

Todas as escolas públicas brasileiras, com jornada parcial ou integral, recebem alimentação escolar gratuitamente, cujos recursos são provenientes, em parte, do Programa Nacional de Alimentação Escolar (PNAE), ação federal de longa trajetória na história da educação brasileira ${ }^{5}$.

Nas escolas com jornada parcial há, pelo menos, uma pausa para o recreio e oferta de alimentação escolar. Nas escolas com jornada integral, é possível haver três (ou mais) pausas: recreio da manhã, almoço e recreio da tarde.

O questionário do Censo Escolar (Formulário Turma) ${ }^{6}$ capta informações sobre as turmas de escolarização. No entanto, são informações relativas ao horário inicial e final de funcionamento da turma, ou seja, o período que os alunos “[...] permanecem em atividades

\footnotetext{
${ }^{5}$ Informações sobre o Programa estão disponíveis em: https://www.fnde.gov.br/index.php/programas/pnae. Acesso em: 10 maio 2019.

${ }^{6}$ Informações sobre o Censo Escolar estão disponíveis em: http://portal.inep.gov.br/web/guest/censo-escolar Acesso em: 10 maio 2019.
} 
escolares (escolarização, refeições e atividades complementares)” (BRASIL, 2018d, p. 28, grifo nosso). Não há dados relativos às pausas para recreio ou almoço separadamente dos outros tempos. $\mathrm{O}$ fato é que, seja na jornada parcial, seja na jornada integral (talvez à exceção de alguns arranjos), o tempo destinado à alimentação escolar ${ }^{7}$ está incorporado na jornada do aluno, sendo concebido como atividade escolar.

Em geral, os tempos para recreio e alimentação escolar são supervisionados pela equipe escolar, possuem um viés educativo e fazem parte da proposta pedagógica da escola (ou deveriam fazer). O importante a destacar é que essas pausas estão incorporadas no tempo do aluno, para efeitos de contabilização da jornada escolar.

\section{Jornada Escolar e Tempo de Cuidado}

Ademais dos tempos destinados ao currículo escolar mínimo, às atividades complementares e às pausas para recreio e alimentação escolar, existe um aspecto temporal que também faz parte da jornada escolar e que aqui se denomina tempo de cuidado.

Geralmente, na jornada escolar parcial, em virtude do constrangimento do horário escolar, o tempo de cuidado é bem sutil e nem sempre é visível. No entanto, ele existe de forma articulada e mesclada aos outros tempos.

À medida que a jornada escolar se amplia, ou seja, que o tempo do aluno na escola se amplia, esse tempo de cuidado passa a ser não apenas necessário, mas também mais visível. Embora mais visível, para efeitos de contabilização da jornada escolar, o tempo de cuidado permanece mesclado aos outros tempos citados anteriormente.

Na prática, nesse exercício de decomposição da jornada escolar, os tempos de cuidado referem-se, por exemplo: ao acolhimento dos alunos na entrada; aos momentos de higienização antes e após a alimentação (higiene das mãos, escovação de dentes); aos momentos de higienização após as atividades físicas e artísticas; aos momentos de saída etc. São tempos de cuidado que, inclusive, demarcam a responsabilidade da escola pelo aluno, por seu bem-estar, por sua saúde e por sua segurança. São aspectos que precisam ser considerados nas propostas pedagógicas das escolas.

\footnotetext{
7 Sobre a questão do recreio como atividade escolar, sugere-se a leitura do Parecer n. 2/2003 do Conselho Nacional de Educação (BRASIL, 2003).
} 


\section{Jornada Escolar, Atividades Escolares e Tipos de Escola}

Do ponto de vista legal, conforme descrito anteriormente, a jornada escolar pode ser parcial, com 4 horas ou mais (até 7 horas) e integral, com 7 horas ou mais. Na prática, as nuances vão muito mais além do montante de horas.

Desde 2007, conforme já indicado, o Censo Escolar, em função da regulamentação do Fundeb, passou a contabilizar as matrículas em tempo integral com base na jornada igual ou superior a 7 horas "[...] compreendendo o tempo total que um mesmo aluno permanece $n a$ escola ou em atividades escolares" (BRASIL, 2007, grifo nosso). Conforme o Censo Escolar, atividades escolares são "[...] aquelas desenvolvidas na escolarização e nas atividades complementares" (BRASIL, 2018d, p. 27).

Para compreender como os entes federativos, as redes de ensino e os estabelecimentos escolares vêm colocando em prática esses preceitos legais, para um exercício de tipificação, denominar-se-á atividades curriculares aquelas associadas ao currículo escolar mínimo (base comum nacional e parte diversificada). Por sua vez, denominar-se-á atividades complementares aquelas relacionadas às atividades complementares, ou seja, destinadas ao enriquecimento curricular.

Conforme sistematizado no Quadro 2, é possível encontrar escolas com jornada parcial, escolas com jornada integral e escolas com jornada mista (parcial e integral). Desejase mostrar que a oferta de atividades complementares, de forma mais ou menos abrangente (parcial ou universal, em termos de alunos atendidos) e com maior ou menor amplitude (perfazendo um total de menos ou mais de 7 horas diárias), demarca as opções e configurações de cada tipo de escola nesse exercício de tipificação.

Quadro 2: Tipos de Escolas em função dos Tipos de Jornada Escolar e Atividades Escolares

\begin{tabular}{|c|c|c|}
\hline JORNADA & TIPO DE ESCOLA & ATIVIDADES \\
\hline PARCIAL & Escola com jornada parcial & $\begin{array}{l}\text { Atividades curriculares, com ou sem oferta de } \\
\text { Atividades complementares que atinjam menos } \\
\text { de } 7 \text { horas (parcela ou totalidade da escola) }\end{array}$ \\
\hline \multirow{2}{*}{ MISTA } & \multirow{2}{*}{$\begin{array}{l}\text { Escola com jornada parcial e } \\
\text { jornada integral }\end{array}$} & $\begin{array}{l}\text { Atividades curriculares, com ou sem oferta de } \\
\text { Atividades complementares que atinjam menos } \\
\text { de } 7 \text { horas a uma parcela da escola. }\end{array}$ \\
\hline & & $\begin{array}{l}\text { Atividades curriculares } \\
\text { complementares, atingindo }\end{array}$ \\
\hline INTEGRAL & Escola com jornada integral & 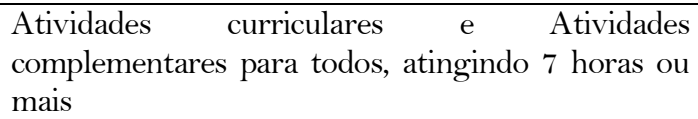 \\
\hline
\end{tabular}

Elaborado pela autora. 
A educação em tempo integral vem aumentando nos últimos anos, ou seja, vem aumentando o número de matrículas com, no mínimo, 7 horas diárias na escola. No entanto, isso não significa, necessariamente, aumento de escolas de tempo integral. Aluno em tempo integral não está diretamente vinculado a escola de tempo integral (na sua totalidade). A jornada escolar mista materializa os elementos de progressividade e seletividade mencionados anteriormente.

Em virtude do grande número de escolas com turnos escolares (2 ou 3 turnos), à exceção da escola com jornada integral para todos, é possível encontrar escolas que oferecem atividades complementares a apenas alguns alunos, turmas, anos de escolarização ou etapas da educação básica. Essa focalização ocorre, geralmente, em função da ausência de espaços físicos. Tais atividades podem ocorrer em espaços multiusos da escola (quadras, pátios, salas de vídeo, biblioteca, sala de leitura, refeitório etc.). No entanto, conforme já destacado, isso apenas é possível quando existe esse tipo de espaço, o que nem sempre é parte da realidade de muitas escolas públicas.

Entretanto, cabe destacar que a ausência histórica de infraestrutura leva, muitas vezes, à oferta de atividades complementares mesmo sem as devidas condições de infraestrutura. Essa opção política, por um lado, inibe o aproveitamento máximo dos benefícios previstos pelas atividades complementares (enriquecimento curricular) e, por outro, pode atrapalhar a oferta adequada do currículo escolar mínimo, já que muitas vezes atividades complementares e atividades curriculares concorrem entre si em termos de espaço físico, material e humano.

\section{Jornada Escolar e Tempo do Aluno na Escola ou sob sua Responsabilidade}

Segundo exposto, apesar dos dois tipos básicos de jornada escolar (parcial e integral), cada um deles pode gerar diferentes possibilidades organizativas a depender das decisões políticas dos entes federativos e das redes de ensino. Inclusive, no âmbito das próprias redes de ensino é possível que coexistam diferentes tipos de escolas, com diferentes tipos de jornada.

Além disso, vem crescendo a noção de ampliação do tempo do aluno na escola ou sob sua responsabilidade, como indica a estratégia 6.1. do Plano Nacional de Educação: "[...] oferta de educação básica pública em tempo integral, [...] de forma que o tempo de permanência $\operatorname{dos}($ as) alunos(as) na escola, ou sob sua responsabilidade, passe a ser igual ou superior a 7 (sete) horas diárias [...]" (BRASIL, 2014a, grifo nosso). As próprias DCN fazem menção à “[...] revisão das referências conceituais quanto aos diferentes espaços e tempos 
educativos, abrangendo espaços sociais na escola e fora dela", indicando que a ampliação da jornada escolar pode ocorrer “[...] em único ou diferentes espaços educativos (BRASIL, 2010, art. $9^{\circ}$, grifo nosso). O Censo Escolar, por sua vez, faz alusão ao tempo integral “[ [...] compreendendo o tempo total em que o aluno permanece na escola ou em atividades escolares em outros espaços educacionais" (BRASIL, 2018b, p. 27, grifo nosso).

As expressões sob sua responsabilidade e em outros espaços educacionais sugerem novos arranjos em termos de oferta educativa, seja no âmbito da escola ou em articulação a ela. Por isso, em alguns casos, as atividades complementares receberiam, explicitamente, o status de extraescolares. O Quadro 3 representa a organização da jornada escolar em função do tempo do aluno na escola, seja por meio da ação direta da escola e de seus agentes, seja por meio da ação de outros agentes educativos e/ou em outros espaços, sob a responsabilidade da escola.

Quadro 3: Tempo do aluno na Escola ou sob sua Responsabilidade

\begin{tabular}{|c|c|c|c|}
\hline JORNADA & TIPO & ATIVIDADES & $\begin{array}{c}\text { ESPAÇO/AGENTES } \\
\text { EDUCATIVOS }\end{array}$ \\
\hline \multirow{3}{*}{ PARCIAL } & \multirow{3}{*}{ Aluno em Tempo Parcial } & Atividades curriculares & Apenas escola \\
\hline & & \multirow{2}{*}{$\begin{array}{l}\text { Atividades curriculares e } \\
\text { Atividades complementares }\end{array}$} & Apenas escola \\
\hline & & & $\begin{array}{l}\text { Escola e outros Espaços/Agentes } \\
\text { educativos }\end{array}$ \\
\hline \multirow[b]{2}{*}{ INTEGRAL } & \multirow[b]{2}{*}{ Aluno em tempo integral } & \multirow{2}{*}{$\begin{array}{l}\text { Atividades curriculares e } \\
\text { Atividades complementares }\end{array}$} & Apenas escola \\
\hline & & & $\begin{array}{l}\text { Escola e outros Espaços/Agentes } \\
\text { educativos }\end{array}$ \\
\hline
\end{tabular}

Elaborado pela autora.

Infelizmente, diante do cenário mencionado anteriormente, muitos desses arranjos (em termos de espaços e de agentes educativos) ocorrem apenas em função da ausência de infraestrutura escolar e dos turnos escolares, condicionando as decisões das redes de ensino e das escolas. Talvez por isso a discussão sobre a articulação da escola com outros espaços, agentes e instituições socioeducativas seja alvo de muitas críticas na área educacional.

Conforme demonstrado, as indicações legais, há tempos, apontam para a possibilidade de novos arranjos para a oferta das atividades complementares de enriquecimento curricular, não em função de restrições orçamentárias, mas sob o argumento de que tais arranjos amplificam as possibilidades de oferta de uma formação integral. Talvez seja o momento de 
amadurecer algumas questões relacionadas à educação não formal, aos espaços não escolares, à intersetorialidade, à territorialidade e às relações público-privadas.

\section{Considerações Finais}

No âmbito político e acadêmico muitos defendem a educação em tempo integral. É tema presente em campanhas eleitorais e muitos estão convencidos de que é o melhor caminho para uma educação pública de qualidade. No entanto, alguns vêm realizando análises superficiais e utilizando argumentos inconsistentes que não expressam os detalhes que devem ser levados em conta para a tomada de decisão política.

No presente artigo optou-se por rever o foco de análise, comumente centrado na educação em tempo integral, e privilegiar a análise da jornada escolar (parcial e integral). Nesse exercício de decomposição da jornada escolar, buscou-se evidenciar os elementos que a constituem e/ou que dividem o cenário com ela.

O exercício permitiu relembrar um aspecto importante: existe uma barreira material relacionada à infraestrutura das escolas públicas e à manutenção dos turnos escolares, o que condiciona a qualidade do currículo escolar mínimo e a possibilidade e/ou abrangência da oferta de atividades complementares.

Embora seja redundante afirmar que há um problema de infraestrutura escolar no Brasil, o artigo destaca a relevância de uma reorientação da política pública. Em lugar de defender a educação em tempo integral para alguns e, portanto, melhorar a infraestrutura daquelas escolas que vão ofertar jornada integral, recomenda-se, primeira e urgentemente, oferecer infraestrutura física e material mínima a todas as escolas, sejam elas com jornada parcial ou integral, o que permitirá o acesso a todos à escolarização obrigatória minimamente de qualidade.

A decomposição da jornada escolar, privilegiando-se a análise do currículo escolar, das atividades complementares, do recreio, da alimentação escolar e do tempo de cuidado serviu para mostrar que qualquer política que pretenda ampliar a jornada escolar precisa considerar esses elementos e como se articulam. Mostrou ainda que o currículo escolar mínimo está vinculado à jornada escolar mínima de 4 horas, pressupondo-se que nesse tempo o básico deve ser garantido a todos. Com base nesse pressuposto, a escolarização obrigatória mínima e de qualidade a todos não estaria submetida ao tipo de jornada (parcial ou integral). 
Demarcadas as diferenças entre o que é básico e o que é complementar na jornada escolar, fica mais fácil compreender que a jornada integral está relacionada ao complementar e ocorre por meio da oferta de atividades complementares/extracurriculares, embora também possam materializar a extensão de conteúdos obrigatórios. Por isso, há que se destacar que a progressividade e a seletividade da educação em tempo integral no Brasil referem-se a decisões sobre quem e como (ainda que provisoriamente) terá direito ao complementar, ou seja, a oportunidades de enriquecimento curricular. É imprescindível que as políticas públicas explicitem como os princípios de igualdade e de equidade estão sendo considerados diante dessas escolhas político-pedagógicas.

Para defender a ampliação da jornada escolar é preciso ter argumentos sólidos que justifiquem mais tempo do aluno na escola. A jornada escolar é uma construção sóciohistórica e cultural. Portanto, os argumentos para ampliação do tempo do aluno na escola também devem ser formulados a partir dessa mesma lógica. Tais argumentos, inclusive, precisam articular perspectivas educacionais e sociais. Ou seja, é preciso considerar as transformações da sociedade, das instituições educativas, dos sujeitos da educação, do papel do Estado e da forma como a ação do Estado se materializa em políticas públicas. Diante desse cenário é preciso definir - de maneira contextualizada e plural - qual jornada escolar atenderá melhor as intencionalidades educativas da sociedade atual.

Para auxiliar no processo de decisão política e estimular o debate acadêmico, algumas questões parecem pertinentes: as políticas de ampliação da jornada escolar devem priorizar uma faixa etária específica da escolarização obrigatória? Deve-se dar preferência aos alunos mais novos ou mais velhos? Deve-se privilegiar grupos e/ou regiões social e economicamente vulneráveis? Como avançar na formulação e implementação de políticas públicas que promovam melhor articulação entre a escola e outros espaços, agentes e instituições socioeducativas para a oferta de atividades complementares?

Garantida a oferta de um currículo escolar mínimo e construídas as bases para o enriquecimento curricular, será possível desenhar, no âmbito de cada escola, uma jornada escolar estreitamente vinculada às necessidades e interesses de cada comunidade escolar, consubstanciando, na prática, o real sentido de uma formação integral. 


\section{Referências}

AMARAL SOBRINHO, J.; PARENTE, M. M. de A. CAIC: solução ou problema? Rio de Janeiro, RJ: IPEA, 1995. 25 p. (Texto para discussão, n. 363).

BRASIL. Lei n. 9.394, de 20 de dezembro de 1996. Estabelece as diretrizes e bases da educação nacional. Disponível em: http://www.planalto.gov.br/ccivil_03/leis/19394.htm Acesso em: 10 maio 2019.

BRASIL. Lei $n . \quad 10.172$, de 9 de janeiro de 2001. Aprova o Plano Nacional de Educação e dá outras providências. Disponível em: http://www.planalto.gov.br/ccivil_03/leis/leis_2001/110172.htm. Acesso em: 25 set. 2019.

BRASIL. Conselho Nacional de Educação. Parecer CEB n. 2/2003. Disponível em: http:/ / portal.mec.gov.br/index.php?option=com_docman\&view=download\&alias=14362pceb002-03\&category_slug=outubro-2013-pdf\&Itemid=30192. Acesso em: 10 maio 2019.

BRASIL. Decreto n. 6.253, de 13 de novembro de 2007. Dispõe sobre o Fundo de Manutenção e Desenvolvimento da Educação Básica e de Valorização dos Profissionais da Educação - FUNDEB [...]. Disponível em: http://www.planalto.gov.br/ccivil_03/_Ato20072010/2007/Decreto/D6253.htm. Acesso em: $10 \quad$ maio 2019 . https://doi.org/10.26512/2015.12.d.20933

BRASIL. Emenda Constitucional n. 59, de 11 de novembro de 2009. Disponível em: http://www.planalto.gov.br/ccivil_03/constituicao/emendas/emc/emc59.htm. Acesso em: 10 maio de 2019.

BRASIL. Conselho Nacional de Educação. Resolução CNE/CEB n. 4, de 13 de junho de 2010. Disponível em: http:// portal.mec.gov.br/dmdocuments/rcebo04_10.pdf. Acesso em: 25 set. 2010.

BRASIL. Lei n. 12.796, de 4 de abril de 2013. Altera a Lei $n^{\circ} 9.394$ [...]. Disponível em: http://www.planalto.gov.br/ccivil_03/_Ato2011-2014/2013/Lei/L12796.htm\#art1.

Acesso em: 25 set. 2019.

BRASIL. Lei n. 13.005, de 25 de junho de 2014a. Aprova o Plano Nacional de Educação - PNE e dá outras providências. Disponível em: http://www.planalto.gov.br/ccivil_03/_ato20112014/2014/lei/113005.htm. Acesso em: 10 maio 2019. https://doi.org/10.1590/s0104$\underline{40602006000100015}$

BRASIL. Ministério da Educação. Instituto Nacional de Estudos e Pesquisas Educacionais Anísio Teixeira. Nota Técnica $n^{o}$ O4O, 17 de dezembro de 2014b. Disponível em: http://download.inep.gov.br/informacoes_estatisticas/indicadores_educacionais/2014/esco la_complexidade_gestao/nota_tecnica_indicador_escola_complexidade_gestao.pdf. Acesso em: 10 maio 2019. https://doi.org/10.1590/s2176-6681/371614642

BRASIL. Lei $n$. 13.515, de 16 de fevereiro de 2017. Altera as Leis $\mathrm{n}^{\circ}$ 9.394, de 20 de dezembro de 1996, que estabelece as diretrizes e bases da educação nacional, e 11.494, de 20 de junho 2007 [...]. Disponível em: http://www.planalto.gov.br/ccivil_03/_Ato20152018/2017/Lei/L13415.htm\#art1. Acesso em: 25 set. 2019. https://doi.org/10.5007/2175$\underline{7941.2017 \mathrm{v} 34 \mathrm{n} 1 \mathrm{p} 1}$ 
BRASIL. Censo da Educação Básica 2018. Indicadores educacionais. Média de horas-aula Diária. Brasília: INEP, 2018a. Disponível em: http://portal.inep.gov.br/web/guest/indicadoreseducacionais. Acesso em: 10 maio 2019. https://doi.org/10.22456/1679-1916.85989

BRASIL. Relatório do $2^{\circ}$ Ciclo de Monitoramento das Metas do Plano Nacional de Educação 2018. Brasília: INEP, 2018b.

BRASIL. Base Nacional Comum Curricular (BNCC). Brasília: MEC; CONSED; UNDIME, $2018 \mathrm{c}$. Disponível

em:

http://portal.mec.gov.br/index.php?option=com_docman\&view=download\&alias=79601-anexotexto-bncc-reexportado-pdf-2\&category slug=dezembro-2017-pdf\&Itemid=30192. Acesso em: 10 maio 2019. https:// doi.org/10.14393/er-v25n3e2018-11

BRASIL. Orientações de preenchimento do Censo Escolar 2018 - programas e políticas federais. Brasília: MEC/INEP, 2018d. Disponível em: http://download.inep.gov.br/educacao_basica/educacenso/situacao_aluno/documentos/2018/ori entacoes_de_preenchimento_censo_escolar_programas\%20e\%20politicas_final.pdf. Acesso em: 25 set. 2019. https://doi.org/10.17648/galoa-cbee-6-29312

CAVAliERE, Ana Maria; COELHO, Ligia Martha. Para onde caminham os CIEPs? Uma análise após 15 anos. Cadernos de Pesquisa, n. 119, p. 147-174, jul. 2003. https://doi.org/10.1590/s0100-15742003000200008

CHIOZZINI, D. F.; MARQUES, S. M. L. O Movimento da Escola Nova, Classes Experimentais e Ginásios Vocacionais (1958-1970). Cadernos de História da Educação, v.15, n.2, p. 582-598, maio/ago. 2016. https://doi.org/10.14393/che-v15n2-2016-7

DALLABRIDA, N. As classes secundárias experimentais: uma tradição escolar (quase) esquecida. Revista Brasileira de História da Educação, Maringá, v. 17, n. 3 (46), p. 196-218, jul./set. 2017. https://doi.org/10.4025/rbhe.v17n3.978

ÉBOLI, T. Uma experiência de educação integral. Brasília: MEC/INEP, 1969.

ESCOLANO BENITO, A. Tiempo y educación. Notas para una genealogía del almanaque escolar. Revista de Educación, n. 298, p. 55-79, 1992.

FARIA FILHO, L. M. de; VIDAL, D. G. Os tempos e os espaços escolares no processo de institucionalização da escola primária no Brasil. Revista Brasileira de Educação, Rio de Janeiro, n. 14, p. 19-34, maio/ago. 2000. https://doi.org/10.1590/s1413-24782009000200003

IBGE. Pesquisa Nacional por Amostra de Domicílios Contínua. Educação 2017. Brasília: IBGE, 2018. Disponível em: https://biblioteca.ibge.gov.br/visualizacao/livros/liv101576_informativo.pdf. Acesso em: 10 maio 2019. https://doi.org/10.21710/rch.v25io.451

MIGNOT, A. C. V. CIEP - Centro Integrado de Educação Pública: alternativa para a qualidade do ensino ou nova investida do populismo na educação? Em Aberto, n. 44, p. 45-63, 1989.

NEVES, J. O ensino público vocacional em São Paulo: renovação educacional como desafio político 1961-1970. 2010. 351f. Universidade de São Paulo - Faculdade de Filosofia, Letras e Ciências Humanas, São Paulo, 2010. https://doi.org/10.11606/t.8.2011.tde-30052011-162911 
OLIVEIRA, F. V. de. Arquitetura escolar paulista dos anos 30. 2007. 140f. Dissertação (Mestrado em História e Fundamentos da Arquitetura e Urbanismo) - Universidade de São Paulo, São Paulo, 2007. https://doi.org/10.23900/2359-1552v8n4-2-2019

PARENTE, C. da M. D. A construção dos tempos escolares. São Cristóvão: Editora UFS, 2015.

PARENTE, C. da M. D. Educação em tempo integral e Programa Mais Educação: aproximações e distanciamentos das regiões brasileiras em relação à meta prevista do projeto de lei do novo Plano Nacional de Educação (PNE). Revista Contrapontos, Itajaí, v. 14, n. 3, p. 618-633, set./dez. 2014. https://doi.org/10.14210/contrapontos.v14n3.p618-633

SILVA, R. N. et al. O descompromisso das políticas públicas com a qualidade do ensino. Cadernos de Pesquisa, São Paulo, n. 84, p. 5-16, fev. 1993.

SOUZA, R. F. de. Tempos de infância, tempos de escola: a ordenação do tempo escolar no ensino público paulista (1892-1933). Educação e Pesquisa, São Paulo, v. 25, n. 2, p. 127-143, jul./dez. 1999. https://doi.org/10.1590/s1517-97021999000200010

XAVIER, C. C. Apontamentos sobre Anísio Teixeira e o Ensino de Arte no Brasil. 2017. 290f. Tese (Doutorado em Arte) - Universidade de Brasília, Instituto de Artes, Brasília, 2017. https://doi.org/10.17143/ciaed/xxiilciaed.2017.00244 